\title{
Effects of GM potato Modena on soil microbial activity and litter decomposition fall within the range of effects found for two conventional cultivars
}

\author{
Karst M. Brolsma ${ }^{1}$ - J Arie Vonk ${ }^{2,3}$ • Ellis Hoffland ${ }^{1}$. \\ Christian Mulder ${ }^{2} \cdot$ Ron GM de Goede ${ }^{1}$
}

Received: 23 March 2015 /Revised: 26 May 2015 / Accepted: 9 June 2015 / Published online: 2 July 2015

(C) The Author(s) 2015. This article is published with open access at Springerlink.com

\begin{abstract}
Plant roots have a profound effect on soil microbial activity, particularly in the rhizosphere. Hence, it is important to understand the potential effects of genetically modified (GM) crops on soil microbial activity and related processes such as litter decomposition. In this study, we compared the effects of GM potato Modena on soil microbial activity and carbon $(\mathrm{C})$ and nitrogen $(\mathrm{N})$ mineralization to effects induced by Modena's parental isoline (Karnico) and a conventional potato cultivar (Aventra). A field experiment was conducted at two sites to assess microbial catabolic diversity (using MicroResp ${ }^{\mathrm{TM}}$ ) in the rhizosphere and in bulk soil, during flowering and senescence of the potato plants. In a laboratory experiment with soil and potato litter from the field experiment, we investigated whether the cultivars had modified the activity of soil microbial communities to such an extent that this affected $\mathrm{C}$ and $\mathrm{N}$ mineralization. Results of the field experiment showed no GM-induced effects on microbial catabolic diversity, while effects of field site location and sampling date were significant. Multivariate analysis including plant traits and soil characteristics revealed that microbial catabolic activities in rhizosphere soil were strongly correlated with soil organic matter and tuber sucrose content, whereas in bulk soil,
\end{abstract}

Ron GM de Goede

ron.degoede@wur.nl

1 Department of Soil Quality, Wageningen University, Box 47, 6700 AA Wageningen, The Netherlands

2 Department for Environmental Effects and Ecosystems, National Institute for Public Health and the Environment (RIVM), Box 1, 3720 BA Bilthoven, The Netherlands

3 Institute for Biodiversity and Ecosystem Dynamics (IBED), University of Amsterdam, Science Park 904, 1098

$\mathrm{XH}$ Amsterdam, The Netherlands they were primarily correlated with soil moisture. In the laboratory experiment, we found that Modena induced a "homefield advantage" in $\mathrm{N}$ mineralization, yet this effect was inconsistent across locations and was also observed for other cultivars. Based on our data and results from previous studies, we conclude that the effects of GM cultivar Modena on soil microbial activity and litter decomposition fall within the normal range of effects found for conventional potato cultivars.

Keywords Solanum tuberosum · Genetically modified crops · Home-field advantage $\cdot$ MicroResp $^{\mathrm{TM}} \cdot$ Carbon and nitrogen mineralization $\cdot$ Risk assessment

\section{Introduction}

Since the commercial introduction of genetically modified (GM) crops in 1996, the total area grown nowadays with GM varieties has increased to 175 million ha, with two thirds of this area located in the Americas (James 2013). In the Netherlands, GM crops are not yet grown commercially due to concerns about possible environmental side effects (e.g., Bruinsma et al. 2003). Depending on the nature of their genetic modification, GM plants could affect soil ecosystems through trait-mediated shifts in root physiology, root exudates, and/or litter quality (Powell 2007). Hence, during the growing season, the effects of GM crops on soil biota are most likely to occur in the rhizosphere, a thin zone around the roots and a hotspot for soil microorganisms (Hartmann et al. 2008). In terms of risk assessment, it is therefore relevant to know whether GM plant-induced changes in the rhizosphere could have prolonged effects on soil biota (Mulder et al. 2006; Powell 2007; Hannula et al. 2014).

Current molecular techniques allow commercial development of marker-free GM crops, i.e., cultivars without plant 
transformation markers such as kanamycin resistance (e.g., Tuteja et al. 2012). Normally, potato (Solanum tuberosum) tubers contain starch consisting of amylose and amylopectin in roughly a 1:5 ratio (Broothaerts et al. 2007), but the cultivar Modena (BASF GmbH, Limburgerhof, Germany) produces tubers with amylose-free starch. This genetic modification was accomplished by inhibiting the transcription of the granule-bound starch synthase gene, which is essential for amylose production, in the parental cultivar Karnico. The resulting amylose-free starch in Modena tubers is an attractive ingredient for a range of industrial applications (Visser and Jacobsen 1993). Since this particular trait involves a direct inhibition of a specific pathway in carbohydrate synthesis and plant transformation markers are absent (De Vetten et al. 2003), any environmental effects of this GM crop may be ascribed to its altered carbohydrate metabolism.

Several studies have assessed the effects of Modena (and similar potato genotypes with genetically modified starch content) on the soil microbial community composition (e.g., Milling et al. 2005; Hannula et al. 2010). The effects of Modena on soil biota were mainly detected in the rhizosphere and during plant senescence, with the effects assumed to be caused by changed root exudation patterns (İnceoğlu et al. 2013). Dias et al. (2013) observed differences between the rhizosphere microbial communities of Modena versus Karnico, in terms of the relative proportions of the gramnegative bacteria Pseudomonas and Burkholderia. However, several studies also showed that plant growth stage, soil type, and yearly fluctuations in weather conditions had more prominent effects on rhizosphere biota, than GM versus conventional potato cultivars (Gschwendtner et al. 2011; Hannula et al. 2012a, b; İnceoğlu et al. 2012, 2013).

The genetically modified carbohydrate metabolism of Modena may not only lead to distinct root exudation patterns but may also affect the biochemical properties of above- and belowground plant parts, resulting in altered litter quality (Jacobsen et al. 1989; Privalle et al. 2013). In turn, this could affect decomposition processes. For example, Hannula et al. (2013) observed that tubers and leaves of Modena decomposed more rapidly than litter of Karnico, although this difference was only observed in the first month of incubation. Furthermore, due to their altered litter quality and root exudation patterns, GM crops such as Modena could influence C and $\mathrm{N}$ mineralization by inducing a "home-field advantage." This term has been used to describe the effect that plant litter decomposes more rapidly in its "home" soil (the location of the plant producing the litter) than in a different soil, because of local adaptation of the soil biota (Ayres et al. 2009).

The first aim of this study was to compare microbial catabolic diversity in rhizosphere and bulk soil from field crops of Modena (GM cultivar), Karnico (parental line), and Aventra (conventional cultivar) and relate the observed effects to potato traits. Our second aim was to investigate in a laboratory experiment whether Modena influenced soil $\mathrm{C}$ and $\mathrm{N}$ mineralization to the extent of inducing a home-field advantage in litter decomposition. We included conventional potato cultivars (Aventra and Karnico) in our experiments to assess whether potential GM trait-related effects would fall within the normal range of variation between conventional cultivars (Griffiths et al. 2007; Perry et al. 2009).

\section{Material and methods}

\section{Field experiment}

The field experiment was performed at two field sites (VMD and BUI), located within $10 \mathrm{~km}$ of each other in the province of Drenthe, The Netherlands. Soil at location VMD was characterized as sandy peat and soil at location BUI as loamy sand. Both soils had similar soil $\mathrm{pH}$, but otherwise differed in various soil characteristics, most importantly organic matter content, sand fraction, and average sand particle size (Table 1). Both fields had been cropped with potato in rotation with barley for many decades.

On 27 April 2011, three different potato cultivars (Karnico, Modena, and Aventra) were planted at both field sites. All varieties are used for potato starch production and have a relative high starch content of the tubers (Hannula et al. 2012b). The variety Modena was bred from Karnico (for details, see De Vetten et al. 2003) and has a much lower amylose content as compared to Karnico and Aventra. Potatoes were planted in a randomized complete block design with four replicate plots per cultivar (12 plots per site). Each plot (3.0× $2.8 \mathrm{~m}$ ) was planted with 28 potato tubers, divided over four ridges; distance between ridges was $75 \mathrm{~cm}$, and planting distance within ridges was $40 \mathrm{~cm}$. Fertilizer application was based on the standard recommendation for potato crops, adjusted to local soil conditions. At location VMD, potatoes were fertilized with $140 \mathrm{~kg} \mathrm{~N} \mathrm{ha}^{-1}, 50 \mathrm{~kg} \mathrm{P}_{2} \mathrm{O}_{5} \mathrm{ha}^{-1}$ (via calcium ammonium nitrate and NP 26-14) and

Table 1 Soil characteristics of the field site locations VMD and BUI (Drenthe, The Netherlands)

\begin{tabular}{llll}
\hline Variable & Unit & VMD & BUI \\
\hline $\mathrm{pH}$ & & 4.6 & 4.6 \\
Organic matter & $\%(w / w)$ & 25.5 & 5.3 \\
Total N & $\mathrm{mg} \mathrm{kg}^{-1}$ & 15.7 & 12.8 \\
Soil moisture & $\mathrm{a}$ & 30.2 & 13.0 \\
Bulk density $_{\text {Silt fraction }}(w / w)$ & 1.38 & 1.05 \\
Sand fraction & $\mathrm{g} \mathrm{cm}{ }^{-3}$ & 2.8 & 5.7 \\
Particle size sand fraction & $\%<16 \mu \mathrm{m}$ & 94.3 & 90.5 \\
\hline
\end{tabular}

${ }^{a}$ Average over both sampling days (August 15 and September 13) 
$1500 \mathrm{~kg}$ protamylasse $\mathrm{ha}^{-1}$ (AVEBE, Veendam, The Netherlands); at location BUI, with $250 \mathrm{~kg} \mathrm{~N} \mathrm{ha}^{-1}$, $250 \mathrm{~kg} \mathrm{~K}_{2} \mathrm{O}$ ha $^{-1}$ (via calcium ammonium nitrate and Patentkali), and 20,000 kg pig slurry ha ${ }^{-1}$.

Potato tuber yield was neither affected by potato variety nor by location. Potato tuber starch, sucrose, vitamin $\mathrm{C}$, and glycoalkaloids were extracted and analyzed as described by Privalle et al. (2013). Potato tubers used for the constituent analyses were sampled from trials located next to the experimental fields.

\section{Collection of soil and litter samples}

At both field site locations, soil samples were taken during the plant flowering stage (15 August 2011) and senescence stage (13 September 2011), since effects were expected to be most pronounced during these growth stages (e.g., İnceoğlu et al. 2013). In each plot, a composite sample of the bulk soil was taken, consisting of 16 cores $(\varnothing 2 \mathrm{~cm}$, depth $20 \mathrm{~cm})$ taken between plants from each of the four ridges. Rhizosphere samples were taken by carefully digging out potato plants using a spade. Soil still adhering to the roots after shaking the plants twice was considered rhizosphere soil, and was collected with a brush. All samples were immediately cooled after sampling $\left(4^{\circ} \mathrm{C}\right)$. For the litter decomposition experiment in the laboratory (see "Laboratory litter decomposition experiment"), we collected bulk soil and plant shoots from each cultivar plot (at both field site locations) on 13 September 2011. Plant samples were dried $\left(70{ }^{\circ} \mathrm{C}\right.$ for $\left.24 \mathrm{~h}\right)$, ground, and analyzed for $\mathrm{C}$ and $\mathrm{N}$ content using flash combustion in an elemental analyzer (Interscience/Fisons EA 1108, The Netherlands) (Pella and Colombo 1973).

\section{Microbial catabolic diversity}

Microbial catabolic diversity was assessed with the MicroResp ${ }^{\mathrm{TM}}$ procedure (Campbell et al. 2003), using a selection of $\mathrm{C}$ substrates based on plant root exudation patterns (Campbell et al. 1997). Within $24 \mathrm{~h}$ after sampling, soil samples were sieved (2-mm mesh) and added to the deepwell plates using the standard filling device to add about $300 \mu \mathrm{l}$ of soil to each well. Soil dry weight per well was calculated based on the weight of fresh soil added and the soil moisture content of the soil sample (determined by drying at $105^{\circ} \mathrm{C}$ for $24 \mathrm{~h}$ ). Filled plates were not pre-incubated, because this could lead to loss of plant-induced rhizosphere effects (Jones and Darrah 1993). The C substrates were dissolved in demineralized water and prepared as stock solutions designed to achieve a final concentration of either $30 \mathrm{mg} \mathrm{C} \mathrm{g}^{-1}$ soil solution (citric acid, glucose, malic acid, sucrose, trehalose, and Tween 80 ) or $7.5 \mathrm{mg} \mathrm{C} \mathrm{g}^{-1}$ soil solution (alanine, arginine, phenylalanine, oxalic acid, and fumaric acid, which have lower solubility), where calculation of the soil solution was based on soil moisture content plus $25 \mu 1$ added stock solution. Substrate solutions, and water as a control, were dispensed into deepwell plates (four replicate wells per substrate, per soil sample). The absorbance of the indicator dye (a solution of cresol red, potassium chloride, sodium bicarbonate in $3 \%$ purified agar) in the detection plates was measured at $570 \mathrm{~nm}$ before and after the incubation period (at $25^{\circ} \mathrm{C}$ for 6 h) using a microplate reader (Vmax, Molecular Devices, Sunnyvale, CA, USA). Color development was normalized by subtracting the time zero measurement (averaged per plate) from the measured color development of the dye in each well after $6 \mathrm{~h}$ of incubation according to Campbell et al. (2003) and converted to $\mathrm{CO}_{2}$ concentrations using the following calibration curve: $\% \mathrm{CO}_{2}=0.002 \times A_{570}{ }^{-3.11}\left(R^{2}=0.93\right)$, where $\% \mathrm{CO}_{2}$ ( $\mathrm{vol} / \mathrm{vol}$ ) is the concentration in the headspace after incubation and $A_{570}$ is the normalized absorbance. Median $\mathrm{CO}_{2}$ concentrations $(n=4)$ for each substrate and plot were converted to respiration rates $\left(\mu \mathrm{g} \mathrm{CO}_{2}-\mathrm{C} \mathrm{g}^{-1}\right.$ dry soil $\mathrm{h}^{-1}$ ), corrected for median respiration rates of the controls (water).

\section{Laboratory litter decomposition experiment}

To assess whether the various potato cultivars could induce a home-field advantage in decomposition, we conducted a laboratory experiment using soil and plant litter (shoots) collected from the field experiment (see "Collection of soil and litter samples"). For each cultivar plot, four bottles $(333 \mathrm{ml})$ were filled each with $75 \mathrm{~g}$ soil (fresh weight) collected from the respective plot on 13 September 2011 (12 plots per site including 4 replicates per cultivar, 2 sites, resulting in 96 bottles). In each of those sets, one bottle was amended with $1.5 \mathrm{~g}$ dried and ground potato shoot litter from the cultivar grown in the same plot as from which the soil was collected (home situation); two bottles received $1.5 \mathrm{~g}$ potato shoot material from one of the other cultivars, grown in other plots within the same experimental block (away situation); and one bottle was kept as a soil-only control (no litter added). The plant material was mixed into the soil, and all bottles were incubated during 121 days in the dark at $20{ }^{\circ} \mathrm{C}$. Soil moisture content was kept at $60 \%$ water holding capacity throughout the experiment.

Carbon mineralization was determined in all bottles, based on $\mathrm{CO}_{2}$ production measured on days $14,17,23,37,65$, and 121 of the incubation. On these days, each bottle was flushed with compressed air for $15 \mathrm{~min}$, closed with an air-tight lid, and incubated for $4 \mathrm{~h}$ at $20^{\circ} \mathrm{C}$ in the dark; after which, the $\mathrm{CO}_{2}$ concentration in the headspace was measured with a Photoacoustic Field Gas-Monitor (INNOVA 1412, LumaSense $^{\mathrm{TM}}$ Technologies, Denmark). C mineralization rates $\left(\mu \mathrm{g} \mathrm{CO}_{2} \mathrm{~g}^{-1}\right.$ dry soil $\left.\mathrm{h}^{-1}\right)$ in soil-litter mixtures were corrected for rates in soil-only incubations. For each replicate cultivar plot, the area under the curve for total net $\mathrm{C}$ 
mineralization over the 121-day incubation period was calculated (Fig. 3).

Home-field advantage was calculated for net $\mathrm{C}$ and $\mathrm{N}$ mineralization and net change in microbial biomass $\mathrm{N}$ over the 121-day incubation period, based on the equations used by Ayres et al. (2009):

$$
\begin{aligned}
& \mathrm{ADH}_{\mathrm{i}}=\mathrm{HDD}_{\mathrm{i}}-\mathrm{ADD}_{\mathrm{i}}-\mathrm{H} \\
& \mathrm{HDD}_{\mathrm{i}}=\left(D_{\mathrm{iI}}-D_{\mathrm{jI}}\right)+\left(D_{\mathrm{iI}}-D_{\mathrm{kI}}\right) \\
& \mathrm{ADD}_{\mathrm{i}}=\left(D_{\mathrm{i} J}-D_{\mathrm{jJ}}\right)+\left(D_{\mathrm{iK}}-D_{\mathrm{kK}}\right) \\
& H=\left(\mathrm{HDD}_{\mathrm{i}}+\mathrm{HDD}_{\mathrm{j}}+\mathrm{HDD}_{\mathrm{k}}\right) /(N-1)
\end{aligned}
$$

where $\mathrm{ADH}$ is the additional decomposition at home for each cultivar; $i, j$, and $k$ represent potato shoot litter from Karnico, Modena, and Aventra, respectively; $I, J$, and $K$ are soil samples from the plots where the potato cultivars Karnico, Modena, and Aventra were grown, respectively; $D$ is a measure of decomposition (net $\mathrm{C}$ or $\mathrm{N}$ mineralization, or net change in microbial biomass $\mathrm{N}$, over the 121-day incubation period); HDD and ADD represent home decomposition difference and away decomposition difference, respectively; $H$ represents the total home-field advantage for all cultivars combined; and $N$ represents the number of cultivars.

Microbial biomass $\mathrm{N}$ was determined on day 0 (in bulk soil samples from each cultivar plot) and day 121 (in all bottles) according to the chloroform fumigation and extraction technique, using $0.5 \mathrm{M} \mathrm{K}_{2} \mathrm{SO}_{4}$ as extractant $(1: 4 \mathrm{w} / \mathrm{v}$, fresh weight basis) $\left(k_{\mathrm{EC}}=0.54\right)$ (Brookes et al. 1985). Total dissolved $\mathrm{N}$ from the non-fumigated subsamples was used to determine the net $\mathrm{N}$ mineralization. Soil mineral $\mathrm{N}$ content was measured on day 0 and day 121 using a segmented flow analyzer (Skalar Analytical, B.V. Breda, The Netherlands). Net change in microbial biomass $\mathrm{N}$ and net $\mathrm{N}$ mineralization in soil-litter incubations over 121 days were corrected for values in soil-only controls.

\section{Data analysis}

In the field experiment, the effects of cultivar, field site location, and sampling date on microbial catabolic activities in the rhizosphere and bulk soil were assessed through redundancy analysis (RDA) in Canoco v. 5.0 (Van Dobben et al. 1999). The significance of correlations between variables was tested using Monte Carlo permutation tests (999 random permutations). As we detected relatively strong effects of field site location and sampling date, we conducted a follow-up RDA analysis including soil characteristics (soil moisture, organic matter) and potato tuber contents (glycoalkaloids, starch, sucrose, and vitamin $\mathrm{C}$ ) as explanatory variables. In this RDA analysis, we used a forward (i.e., stepwise) selection of explanatory variables to select the variables comprising the strongest effects and to sort out variance already explained by previously selected variables. Block effects were partialled out by entering block indicator variables as covariables. Explanatory variables showing significant correlations $(p \leq$ 0.05 ) with microbial catabolic diversity (response to specific substrates) were included in ordination plots (Fig. 1).

In the soil-litter incubation experiment, ANOVA was used to analyze the effects of cultivar, field site location (BUI versus VMD), and the interaction between these factors on decomposition-related variables ( $\mathrm{C}$ and $\mathrm{N}$ mineralization and microbial biomass N). Data from the soil-only controls (basal decomposition) were analyzed separately; ANOVA of decomposition variables in soil-litter mixtures focussed on home situations (i.e., treatments where soil and litter came from one and the same plot). An additional ANOVA was conducted to analyze cultivar and field site location effects on the C:N ratio of potato shoot litter.

To assess whether the different potato cultivars induced a home-field advantage in decomposition, we calculated the average and $95 \%$ confidence interval (average $\pm 1.96 \times \mathrm{SE}$ ) for the additional decomposition at home (ADH; see "Laboratory litter decomposition experiment") for net $\mathrm{C}$ and

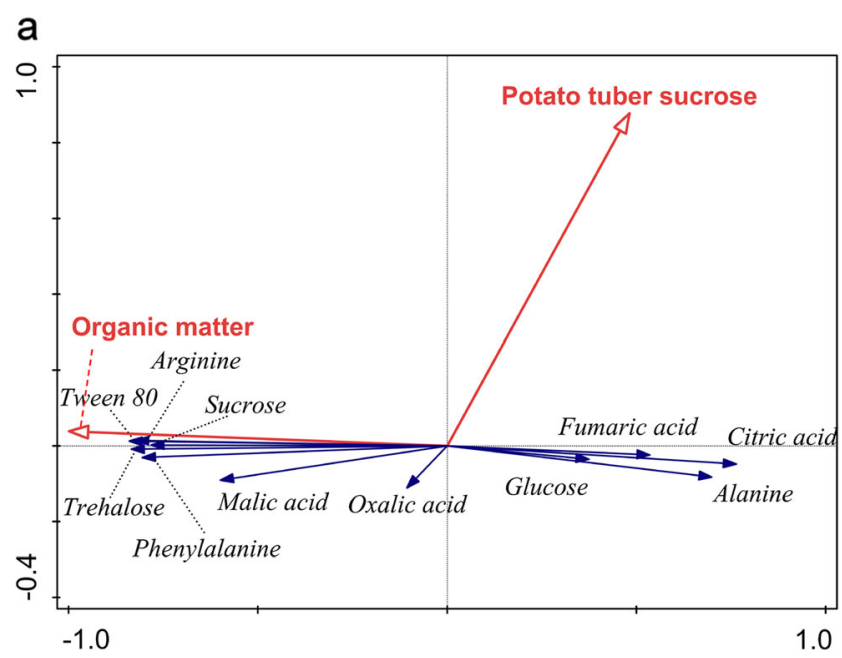

b

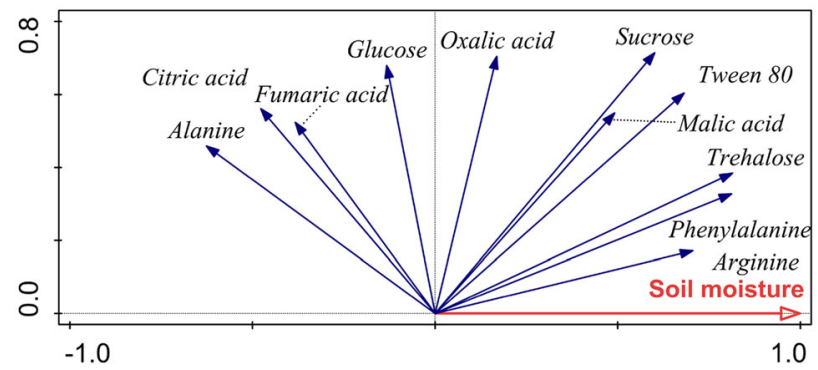

Fig. 1 RDA ordination diagram of microbial catabolic response to various substrates in a rhizosphere soil and $\mathbf{b}$ bulk soil of three potato cultivars grown at two field site locations. In (a), tuber sucrose content and soil organic matter are included as explanatory variables (accounting for $63.6 \%$ of total variance in microbial catabolic diversity); in (b), the main explanatory variable is soil moisture (accounting for $43.4 \%$ of total variance) 
$\mathrm{N}$ mineralization and net change in microbial biomass $\mathrm{N}$ over the 121-day incubation period, assuming a normal distribution of the data. Where the $95 \%$ confidence interval of ADH did not include zero, we considered the home-field advantage $(\mathrm{ADH}>0)$ or home-field disadvantage $(\mathrm{ADH}<0)$ to be significant.

\section{Results}

\section{Field experiment: microbial catabolic diversity in rhizosphere and bulk soil}

In the field experiment, microbial catabolic activity was not significantly affected by potato cultivar, neither in rhizosphere nor bulk soil. Instead, RDA detected significant effects of field site location and sampling date, both in rhizosphere soil (location effect $67.3 \%$ explained variance, $F=85.2, p<0.002$; sampling date effect $4.8 \%$ explained variance, $F=3.1, p=$ 0.02 ) and in bulk soil (location effect $53.3 \%$ explained variance, $F=47.8, p<0.002$; sampling date effect $16.1 \%$ explained variance, $F=8.9, p<0.002$ ).

The follow-up redundancy analysis, including specific cultivar traits and soil characteristics as explanatory variables, showed that microbial catabolic activities in rhizosphere soil were most strongly correlated with soil organic matter and tuber sucrose content, whereas in bulk soil, they were primarily correlated with soil moisture (Table 2). Specifically, in rhizosphere soil, microbial response to sucrose, arginine, Tween 80 , trehalose, phenylalanine, and malic acid was found to be positively correlated with soil organic matter, whereas microbial response to fumaric acid, citric acid, alanine, and glucose was negatively correlated with soil organic matter (Fig 1a). In addition, microbial response to arginine, phenylalanine, trehalose, Tween 80 , malic acid, sucrose, and oxalic acid was negatively correlated with potato tuber sucrose content. In bulk soil, microbial response to arginine, phenylalanine, trehalose, Tween 80 , malic acid, and sucrose was positively correlated with soil moisture, whereas response to fumaric acid, citric acid, and alanine was negatively correlated with soil moisture (Fig. 1b).

\section{Laboratory experiment: potato litter decomposition}

The C:N ratio of the potato shoot litter used in the decomposition experiment neither was significantly different between cultivars $(F=3.30, p=0.07)$ nor was it significantly influenced by which field site (BUI or VMD) the plants had grown ( $F=$ 2.98, $p=0.11$ ) (Fig. 2). Decomposition of this material in soillitter incubations was significantly influenced by location in terms of which field site the soil and litter had been derived from (BUI or VMD); however, no effect of cultivar was found: whether the soil and litter originated from plots with Karnico, Modena, or Aventra did not significantly affect decomposition variables, at least in home situations (Table 3). In general, decomposition rates were higher in soil derived from location VMD than from BUI (Fig. 3). At location VMD, the C mineralization rate of Aventra litter in Aventra soil was lower as compared to Karnico litter in Karnico soil and Modena litter in Modena soil for the first 23 days of incubation (Fig. 3a). At location BUI, the $\mathrm{C}$ mineralization rate of Aventra litter in Aventra soil as compared to Karnico litter in Karnico soil and Modena litter in Modena soil was lower at day 65 of incubation. After 121 days of incubation, mineral $\mathrm{N}$ was higher in all soil-litter incubations, compared to soil-only incubations (Fig. 4a). However, microbial biomass $\mathrm{N}$ was only found to be higher in soil-litter incubations (compared to soil-only incubations) if the soil was derived from location VMD (Fig. 4b).

When comparing all treatments (both home situations and away situations), we detected a home-field advantage effect of Modena (if soil and litter were derived from VMD) and Karnico (soil and litter from BUI) on net $\mathrm{N}$ mineralization (Table 4). Furthermore, we found a significant home-field disadvantage effect of Aventra on $\mathrm{N}$ mineralization, regardless of whether the soil and litter were derived from location VMD

Table 2 Effects of potato tuber contents and soil characteristics on microbial catabolic diversity in rhizosphere and bulk soil of three potato cultivars (Aventra, Karnico, and Modena), grown at two field site locations (VMD and BUI) (\% variance explained, pseudo- $F$ and $p$ values based on RDA)

\begin{tabular}{|c|c|c|c|c|c|c|c|c|}
\hline & \multirow[t]{2}{*}{ Variable } & \multirow[t]{2}{*}{ Unit } & \multicolumn{3}{|c|}{ Rhizosphere soil } & \multicolumn{3}{|l|}{ Bulk soil } \\
\hline & & & $\operatorname{Var}(\%)$ & $F$ & $p$ & $\operatorname{Var}(\%)$ & $F$ & $p$ \\
\hline \multirow[t]{4}{*}{ Potato } & Glycoalkaloids & $\mathrm{mg} \mathrm{kg}^{-1}$ fresh weight & 0.6 & 0.8 & 0.49 & 1.2 & 1.0 & 0.31 \\
\hline & Starch & $\mathrm{g} 100 \mathrm{~g}^{-1}$ fresh weight & 1.6 & 2.2 & 0.09 & 0.3 & 0.2 & 0.95 \\
\hline & Sucrose & g $100 \mathrm{~g}^{-1}$ fresh weight & 2.4 & 3.1 & 0.03 & 0.2 & 0.2 & 0.94 \\
\hline & Vitamin C & $\mathrm{mg} 100 \mathrm{~g}^{-1}$ fresh weight & 1.0 & 1.2 & 0.27 & 0.4 & 0.3 & 0.85 \\
\hline \multirow[t]{2}{*}{ Soil } & Organic matter & $\%(w / w)$ & 65.1 & 80.2 & $<0.002$ & 0.2 & 0.2 & 0.97 \\
\hline & Moisture & $\%(w / w)$ & 0.5 & 0.6 & 0.72 & 48.8 & 41.0 & $<0.002$ \\
\hline
\end{tabular}

Significant explanatory variables in italics. Extraction and analysis following Privalle et al. (2013) 


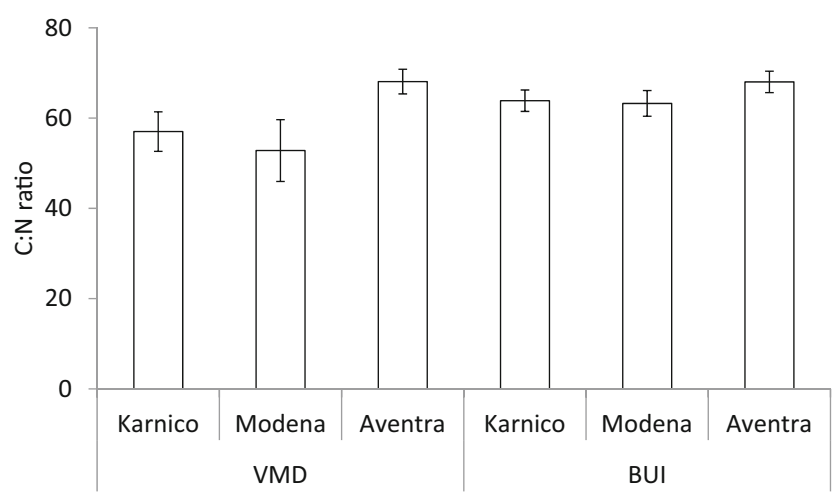

Fig. $2 \mathrm{C}: \mathrm{N}$ ratios of shoot litter from potato cultivars Karnico, Modena, and Aventra, grown at two field site locations (VMD and BUI). Based on ANOVA, no significant effects of cultivar or location were observed. Error bars represent standard errors of the mean $(n=4)$

and BUI. No home-field advantage (or disadvantage) effects were observed with regard to other decomposition variables ( $\mathrm{C}$ mineralization and microbial biomass $\mathrm{N}$ ).

\section{Discussion}

In this study, we assessed the effects of GM potato cultivar Modena on soil microbial activity and decomposition processes and compared these to effects induced by the parental line (Karnico) and a conventional cultivar (Aventra), both in the field and in a laboratory experiment. In the field experiment, effects of Modena on microbial catabolic diversity fell within the same range as effects induced by the non-GM potato varieties, both in rhizosphere and bulk soil. In the laboratory experiment, we detected cultivar-specific effects on $\mathrm{N}$ mineralization only, in terms of a home-field advantage effect of Modena (if soil and litter were derived from location VMD) and Karnico (soil and litter from BUI). Potato cultivar Aventra was found to induce a home-

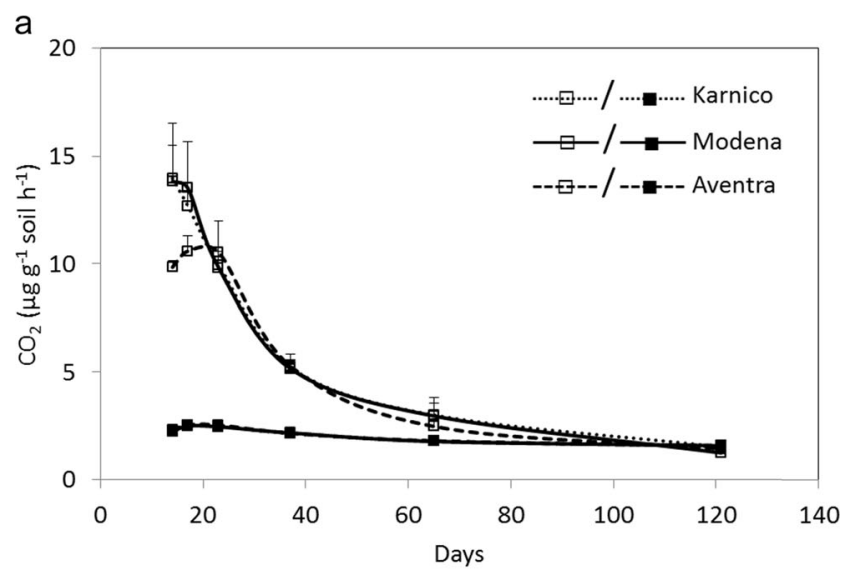

b

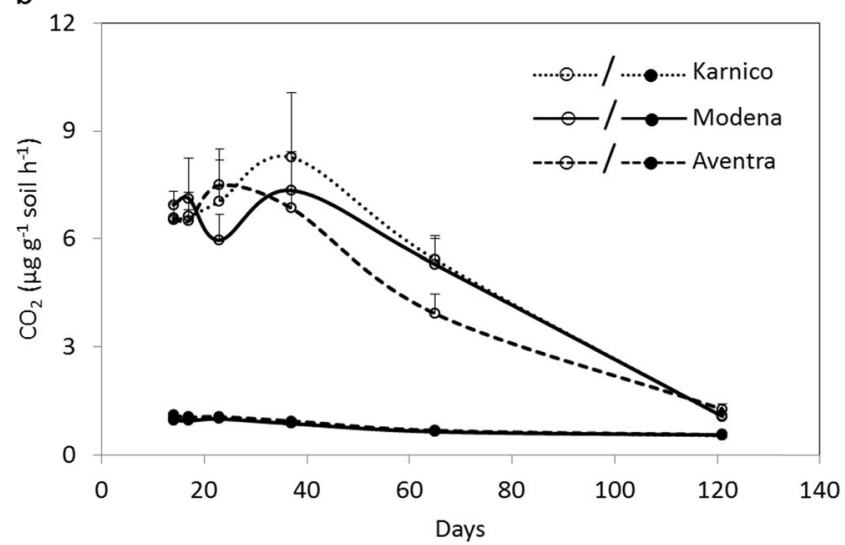

Fig. 3 Carbon mineralization in 121-day incubations of soil-only (closed symbols: basal mineralization) or potato litter-soil mixtures (open symbols: litter-induced mineralization), with soil and litter derived from potato crops (Karnico, Modena, and Aventra) grown at two field site locations: a VMD and b BUI. Data include home situations only (i.e., incubations with soil and litter from the same cultivar plot). Bars represent standard errors of the mean (positive direction only) $(n=4)$. Litter-induced mineralization rates have been corrected for basal mineralization

field disadvantage in net $\mathrm{N}$ mineralization, in soil-litter incubations from both VMD and BUI.
Table 3 Effects of cultivar (Karnico, Modena, and Aventra) and field site location (VMD and BUI) on $\mathrm{C}$ mineralization, $\mathrm{N}$ mineralization, and microbial biomass $\mathrm{N}$ in soil-only and soillitter incubations (with soil and litter derived from the same cultivar plots: home situations)

\begin{tabular}{|c|c|c|c|c|c|c|c|}
\hline & & \multicolumn{2}{|c|}{$\mathrm{C}$ mineralization } & \multicolumn{2}{|c|}{$\mathrm{N}$ mineralization } & \multicolumn{2}{|c|}{ Microbial biomass $\mathrm{N}$} \\
\hline & & $F$ & $p$ & $F$ & $p$ & $F$ & $p$ \\
\hline \multirow[t]{3}{*}{$\mathrm{Basal}^{\mathrm{a}}$} & Cultivar (Cv) & 0.13 & 0.88 & 0.12 & 0.89 & 3.08 & 0.08 \\
\hline & Location (L) & 631.40 & $<0.001$ & 190.19 & $<0.001$ & 3.20 & 0.09 \\
\hline & $\mathrm{Cv} \times \mathrm{L}$ & 0.03 & 0.98 & 0.20 & 0.82 & 2.42 & 0.12 \\
\hline \multirow[t]{3}{*}{ Litter induced $^{\mathrm{b}}$} & Cultivar (Cv) & 1.28 & 0.31 & 2.40 & 0.12 & 1.11 & 0.36 \\
\hline & Location (L) & 35.31 & $<0.001$ & 2.10 & 0.17 & 12.93 & 0.003 \\
\hline & $\mathrm{Cv} \times \mathrm{L}$ & 0.22 & 0.81 & 0.56 & 0.58 & 0.26 & 0.78 \\
\hline
\end{tabular}

Significant results (ANOVA) in italics $(n=4)$

${ }^{a}$ Values measured in soil-only incubations

${ }^{\mathrm{b}}$ Values measured in soil-litter mixtures, corrected for values measured in soil-only incubations 

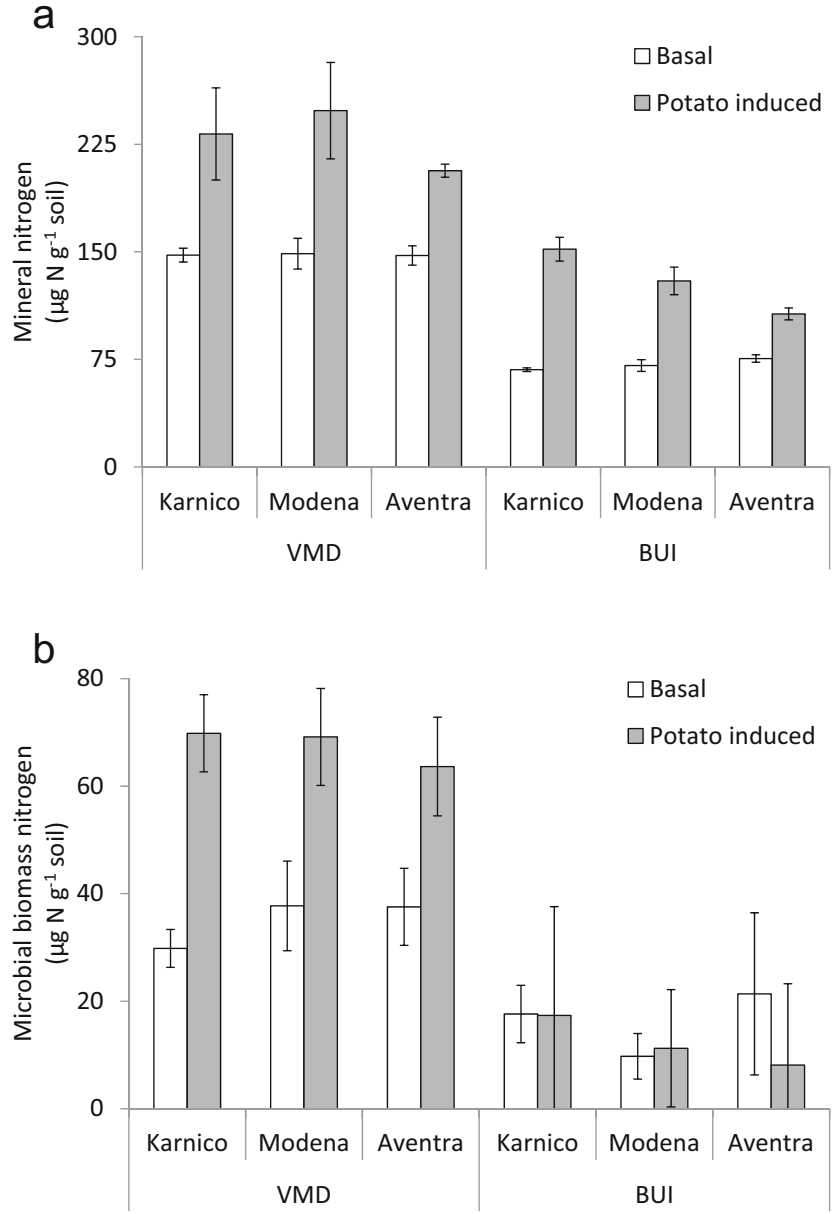

Fig. 4 Net change in a mineral $\mathrm{N}$ and $\mathbf{b}$ microbial biomass $\mathrm{N}$ over 121 days in incubations of soil-only (open bars: basal) and potato littersoil mixtures (closed bars litter induced), with soil and litter derived from potato crops (Karnico, Modena, and Aventra) grown at two field site locations (VMD and BUI). Data include home situations only (i.e., incubations with soil and litter from the same cultivar plot). Bars represent standard errors of the mean $(n=4)$. Litter-induced mineralization rates have been corrected for basal mineralization

\section{The field experiment}

As said, microbial catabolic diversity did not differ significantly between field crops of the potato cultivars investigated, in rhizosphere nor bulk soil. However, multivariate analyses (RDA) indicated that a significant proportion of the variation in microbial catabolic diversity could be related to soil characteristics (soil moisture, organic matter) and plant traits (in particular, tuber sucrose content). Soil organic matter, a source of nutrients and energy, differed significantly between the two field locations (Table 1), and this had an overriding influence on the soil microbial activity, as has been observed in other studies (e.g., Fierer et al. 2009). In addition to organic matter, environmental factors such as temperature and water conditions also affect microbial activity. Orchard and Cook (1983) observed that soil water potential showed a positive log-linear relationship with soil microbial activity, as long as the latter was not limited by substrate availability, which is correlated to organic matter content. Such strong links between soil moisture and organic matter are well known (e.g., Gupta and Larson 1979; Vereecken et al. 1989) and were also observed in our study. Hence, the observed difference between the driving factors of microbial catabolic diversity in the rhizosphere (organic matter) versus bulk soil (soil moisture) is only relative.

Although we found notable differences between the microbial catabolic activity patterns of the two (BUI and VMD) locations, we found these activity patterns to be highly similar between the rhizosphere and bulk soil within the same location. At location VMD (loamy peat: high organic matter and moisture content), microorganisms in both rhizosphere and bulk soil were strongly activated on the same set of substrates (sucrose, arginine, Tween 80, trehalose, phenylalanine, and, to a lesser extent, malic acid). The soil microbial community at location BUI (loamy sand: low organic matter and moisture
Table 4 Estimation of homefield advantage $(\mathrm{ADH})$ in litter decomposition, in terms of net $\mathrm{C}$ mineralization, $\mathrm{N}$ mineralization, and change in microbial biomass $\mathrm{N}$ over 121 days, in laboratory incubations of soil and litter derived from three potato cultivars (Karnico, Modena, and Aventra) grown at two field site locations (VMD and BUI)

\begin{tabular}{|c|c|c|c|c|c|c|c|}
\hline & & \multicolumn{2}{|c|}{$\mathrm{C}$ mineralization } & \multicolumn{2}{|c|}{$\mathrm{N}$ mineralization } & \multicolumn{2}{|c|}{ Microbial biomass $\mathrm{N}$} \\
\hline & & \multicolumn{2}{|l|}{$\mathrm{ADH}$} & \multicolumn{2}{|l|}{$\mathrm{ADH}$} & \multicolumn{2}{|l|}{$\mathrm{ADH}$} \\
\hline & & Average & $95 \% \mathrm{Cl}^{\mathrm{a}}$ & Average & $95 \% \mathrm{CI}$ & Average & $95 \% \mathrm{CI}$ \\
\hline \multirow[t]{3}{*}{ VMD } & Karnico & 0.78 & $(-4.20-5.76)$ & 0.62 & $(-0.29-1.53)$ & 0.21 & $(-0.62-1.03)$ \\
\hline & Modena & 1.84 & $(-1.33-5.01)$ & $1.02^{\mathrm{b}}$ & $(0.20-1.84)$ & -0.13 & $(-0.85-0.60)$ \\
\hline & Aventra & -2.01 & $(-5.24-1.23)$ & $-1.61^{\mathrm{c}}$ & $(-3.03--0.19)$ & -0.04 & $(-0.74-0.66)$ \\
\hline \multirow[t]{3}{*}{ BUI } & Karnico & -0.77 & $(-4.17-2.62)$ & $0.62^{\mathrm{b}}$ & $(0.08-1.15)$ & -0.29 & $(-0.69-0.12)$ \\
\hline & Modena & 0.10 & $(-1.92-2.13)$ & 0.26 & $(-0.55-1.07)$ & -0.07 & $(-1.40-1.26)$ \\
\hline & Aventra & 1.21 & $(-2.38-4.80)$ & $-0.90^{\mathrm{c}}$ & $(-1.66--0.15)$ & 0.35 & $(-0.67-1.37)$ \\
\hline
\end{tabular}

Significant results in italics $(n=4)$

${ }^{\text {a }}$ Confidence interval

${ }^{\mathrm{b}}$ Home-field advantage (ADH $>0$ )

${ }^{\mathrm{c}}$ Home-field disadvantage $(\mathrm{ADH}<0)$ 
content) responded to a different subset of substrates (alanine, citric acid, and, to a lesser extent, fumaric acid and glucose), again without differences between rhizosphere and bulk soil. Our results show that the MicroResp ${ }^{\mathrm{TM}}$ methodology was effective in differentiating distinct microbial rhizosphere communities, as found by Knox et al. (2014) and Dieng et al. (2014). The absence of differences between rhizosphere and bulk soil suggests that either the microbial communities were not significantly affected by the potato roots or that the methodology was not sensitive enough to detect relatively small effects on the microbial activity.

The only potato cultivar-related effect detected was the effect of tuber sucrose content, which explained $2.4 \%$ of the variation in rhizosphere microbial respiration. It seems unlikely that tuber sucrose directly affected the rhizosphere microbial community through sucrose as a leachate, because experimental addition of sucrose to rhizosphere soil from potato tubers with high tuber sucrose content resulted in reduced, rather than increased, microbial activity (MicroResp ${ }^{\mathrm{TM}}$; Fig. 1a). However, the MicroResp ${ }^{\mathrm{TM}}$ tests did show a positive (albeit small) effect of glucose, which is the breakdown product of sucrose, on the activity of the rhizosphere microbial community of high tuber sucrose potato tubers. These results suggest that the potato plants did have some effect on the activity of rhizosphere microorganisms, but any effects in bulk soil remained below the detection limit of the MicroResp ${ }^{\mathrm{TM}}$ method.

\section{The laboratory experiment}

In the laboratory experiment, potato cultivar effects were observed for $\mathrm{N}$ mineralization, but not for $\mathrm{C}$ mineralization or microbial biomass $\mathrm{N}$. In soil-only incubations, and in soillitter incubations in which litter and soil had been derived from the same cultivar plots (home situations), cultivar had no detectable effect on decomposition variables. However, similar to our field observations, decomposition processes were significantly different between field site locations, with generally higher decomposition rates in incubations with soil derived from location VMD (high in organic matter) than from BUI (low organic matter). When comparing decomposition processes in home situations (soil and litter from the same cultivar plot) and away situations (soil and litter from different cultivar plots), some cultivar effects were detected, in terms of a home-field advantage effect of Modena (if soil and litter were derived from location VMD) and Karnico (soil and litter from BUI) on net N mineralization. Furthermore, Aventra was found to induce a home-field disadvantage in net $\mathrm{N}$ mineralization, in soil-litter incubations from both VMD and BUI. A home-field (dis)advantage generally results from changes in the decomposer community or differences in litter quality (Ayres et al. 2009). However, our MicroResp ${ }^{\mathrm{TM}}$ measurements did not indicate any significant differences between cultivars in terms of the microbial catabolic diversity in the bulk soil used for the incubation experiment nor did we find statistically significant differences in terms of litter C:N ratio (Fig. 2). Possibly, the observed home-field (dis)advantages were related to interactions between litter $\mathrm{N}$ and decomposer communities (Perez et al. 2013). The generally weak homefield effects found in our soil-litter incubations could be explained by the short duration of the field experiment from which the soil and litter were derived: in other studies measuring home-field effects, the plant-soil system had been in place for many more growing seasons than in our study (e.g., forests in Ayres et al. 2009).

\section{Conclusions}

We showed that soil microorganisms and related decomposition processes were not affected to a detectable degree by GM potato cultivar Modena, when compared with the parental line and a conventional cultivar. Our results also demonstrate the relevance of including variation in soil characteristics (e.g., effects of moisture conditions on respiration (Shi and Marschner 2015)), while quantifying effects induced by specific potato traits such as tuber sucrose content. Our results are in line with previous investigations on the effects of Modena on soil biota and soil processes (Hannula et al. 2012a, b; İnceoğlu et al. 2012; Vervoort 2013), which all indicate that this particular GM potato cultivar has either no measurable or no consistent effects on soil ecosystems, when compared to conventional cultivars. Based on the relevance of the soil biota investigated in these studies (bacteria, fungi, and nematodes; Hannula et al. 2012a, b; İnceoğlu et al. 2012; Vervoort 2013), which include effects on soil biodiversity, biomass distribution across trophic levels, and food web topologies, we conclude that Modena is unlikely to significantly affect soil ecosystems in terms of specific effects due to its genetic modification. However, it must be underlined that the results of these studies, including our experiments, concern the effects of a single plant trait, i.e., the knockdown of a specific gene in the carbohydrate metabolism of potato, and cannot be translated to other genetic modifications or other GM crops.

Acknowledgments We thank Maaike Bruinsma and Andreas Plischke for their collaboration in the field experiment and Jet Vervoort and Renée van der Salm for their help with the experimental work. Peter Bruinenberg and Paul Heeres from AVEBE/Karna and Thorsten Storck, Andreas Heise, and Christine Wandelt from BASF Plant Science Company $\mathrm{GmbH}$ are acknowledged for allowing us to take soil and plant samples from their experimental fields and to use their potato trait data. Christien Ettema from Shades of Green-De Groene Vertaler is acknowledged for improving the English. We are grateful to the two anonymous reviewers for their time and valuable suggestions for improvement on an earlier draft of this article. This research was financially supported by ERGO grants 838.06.061, 838.06.063, and 838.06.064 of the Netherlands Organization for Scientific Research (NWO, The Hague). 
Open Access This article is distributed under the terms of the Creative Commons Attribution 4.0 International License (http:// creativecommons.org/licenses/by/4.0/), which permits unrestricted use, distribution, and reproduction in any medium, provided you give appropriate credit to the original author(s) and the source, provide a link to the Creative Commons license, and indicate if changes were made.

\section{References}

Ayres E, Steltzer H, Berg S, Wall DH (2009) Soil biota accelerate decomposition in high-elevation forests by specializing in the breakdown of litter produced by the plant species above them. J Ecol 97:901912

Brookes PC, Landman A, Pruden G, Jenkinson DS (1985) Chloroform fumigation and the release of soil nitrogen: a rapid direct extraction method to measure microbial biomass nitrogen in soil. Soil Biol Biochem 17:837-842

Broothaerts W, Corbisier P, Emons H, Emteborg H, Linsinger TPJ, Trapmann S (2007) Development of a certified reference material for genetically modified potato with altered starch composition. J Agric Food Chem 55:4728-4734

Bruinsma M, Kowalchuk GA, Van Veen JA (2003) Effects of genetically modified plants on microbial communities and processes in soil. Biol Fertil Soils 37:329-337

Campbell CD, Chapman SJ, Cameron CM, Davidson MS, Potts JM (2003) A rapid microtiter plate method to measure carbon dioxide evolved from carbon substrate amendments so as to determine the physiological profiles of soil microbial communities by using whole soil. Appl Environ Microbiol 69:3593-3599

Campbell CD, Grayston SJ, Hirst DJ (1997) Use of rhizosphere carbon sources in sole carbon source tests to discriminate soil microbial communities. J Microbiol Methods 30:33-41

De Vetten N, Wolters A-M, Raemakers K, Van der Meer I, Ter Stege R, Heeres E, Heeres P, Visser R (2003) A transformation method for obtaining marker-free plants of a cross-pollinating and vegetatively propagated crop. Nat Biotechnol 21:439-442

Dias ACF, Dini-Andreote F, Hannula SE, Andreote FD, Pereira E, Silva MDC, Salles JF, De Boer W, Van Veen J, Van Elsas JD (2013) Different selective effects on rhizosphere bacteria exerted by genetically modified versus conventional potato lines. PLoS One 8 , e67948

Dieng A, Ndoye I, Duponnois R, Baudoin E (2014) Effects of Jatropha curcas L. plantation on soil bacterial and fungal communities. Soil Biol Biochem 72:105-115

Fierer N, Strickland MS, Liptzin D, Bradford MA, Cleveland CC (2009) Global patterns in belowground communities. Ecol Lett 12:12381249

Griffiths BS, Caul S, Thompson J, Birch ANE, Cortet J, Andersen MN, Krogh PH (2007) Microbial and microfaunal community structure in cropping systems with genetically modified plants. Pedobiologia 51:195-206

Gschwendtner S, Esperschütz J, Buegger F, Reichmann M, Müller M, Munch JC, Schloter M (2011) Effects of genetically modified starch metabolism in potato plants on photosynthate fluxes into the rhizosphere and on microbial degraders of root exudates. FEMS Microbiol Ecol 76:564-575

Gupta SC, Larson WE (1979) Estimating soil water retention characteristics from particle size distribution, organic matter percent, and bulk density. Water Resour Res 15:1633-1635

Hannula SE, De Boer W, Van Veen JA (2010) In situ dynamics of soil fungal communities under different genotypes of potato, including a genetically modified cultivar. Soil Biol Biochem 42:2211-2223
Hannula SE, Boschker HTS, De Boer W, Van Veen JA (2012a) ${ }^{13}$ C pulselabeling assessment of the community structure of active fungi in the rhizosphere of a genetically starch-modified potato (Solanum tuberosum) cultivar and its parental isoline. New Phytol 194:784 799

Hannula SE, De Boer W, Van Veen JA (2012b) A 3-year study reveals that plant growth stage, season and field site affect soil fungal communities while cultivar and GM-trait have minor effects. PLoS One 7, e33819

Hannula SE, De Boer W, Baldrian P, Van Veen JA (2013) Effect of genetic modification of potato starch on decomposition of leaves and tubers and on fungal decomposer communities. Soil Biol Biochem 58:88-98

Hannula SE, De Boer W, Van Veen JA (2014) Do genetic modifications in crops affect soil fungi? A review. Biol Fertil Soils 50:433-446

Hartmann A, Schmid M, Van Tuinen D, Berg G (2008) Plant-driven selection of microbes. Plant Soil 321:235-257

İnceoğlu Ö, Falcão Salles J, Van Elsas JD (2012) Soil and cultivar type shape the bacterial community in the potato rhizosphere. Microb Ecol 63:460-470

İnceoğlu Ö, Van Overbeek LS, Salles JF, Van Elsas JD (2013) Normal operating range of bacterial communities in soil used for potato cropping. Appl Environ Microbiol 79:1160-1170

Jacobsen E, Hovenkamp-Hermelink JHM, Krijgsheld HT, Nijdam H, Pijnacker LP, Witholt B, Feenstra WJ (1989) Phenotypic and genotypic characterization of an amylose-free starch mutant of the potato. Euphytica 44:43-48

James C (2013) Global status of commercialized biotech/GM crops: 2013. ISAAA Briefs No 46, Ithaca, NY

Jones DL, Darrah PR (1993) Re-sorption of organic compounds by roots of Zea mays L. and its consequences in the rhizosphere. II Experimental and model evidence for simultaneous exudation and re-sorption of soluble C compounds. Plant Soil 153:47-59

Knox OGG, Gupta VVSR, Lardner R (2014) Field evaluation of the effects of cotton variety and GM status on rhizosphere microbial diversity and function in Australian soils. Aust J Soil Res 52:203-2015

Milling A, Smalla K, Maidl FX, Schloter M, Munch C (2005) Effects of transgenic potatoes with an altered starch composition on the diversity of soil and rhizosphere bacteria and fungi. Plant Soil 266:23-39

Mulder C, Wouterse M, Raubuch M, Roelofs W, Rutgers M (2006) Can transgenic maize affect soil microbial communities? PLoS Comput Biol 2, e128

Orchard V, Cook F (1983) Relationship between soil respiration and soil moisture. Soil Biol Biochem 15:447-453

Pella E, Colombo B (1973) Study of carbon, hydrogen and nitrogen determination by combustion-gas chromatography. Mikrochim Acta 61:697-719

Perez G, Aubert M, Decaëns T, Trap J, Chauvat M (2013) Home-field advantage: a matter of interaction between litter biochemistry and decomposer biota. Soil Biol Biochem 67:245-254

Perry JN, Ter Braak CJ, Dixon PM, Duan JJ, Hails RS, Huesken A, Laviell M, Marvier M, Scardi M, Schmidt K, Tothmeresz B, Schaarschmidt F, Van der Voet H (2009) Statistical aspects of environmental risk assessment of GM plants for effects on non-target organisms. Environ Biosaf Res 8:65-78

Powell JR (2007) Linking soil organisms within food webs to ecosystem functioning and environmental change. Adv Agron 96:307-350

Privalle LS, Gillikin N, Wandelt C (2013) Bringing a transgenic crop to market: where compositional analysis fits. J Agric Food Chem 61: $8260-8266$

Shi A, Marschner P (2015) The number of moist days determines respiration in drying and rewetting cycles. Biol Fertil Soils 51:33-41

Tuteja N, Verma S, Sahoo RK, Raveendar S, Reddy IBL (2012) Recent advances in development of marker-free transgenic plants: regulation and biosafety concern. J Biosci 37:169-197 
Van Dobben HF, Ter Braak CJF, Dirkse GM (1999) Undergrowth as a biomonitor for deposition of nitrogen and acidity in pine forest. For Ecol Manag 114:83-95

Vereecken H, Maes J, Feyen J, Darius P (1989) Estimating the soil moisture retention characteristic from texture, bulk density, and carbon content. Soil Sci 148:389-403
Vervoort MTW (2013) Covering ground: insights into soil ecology by molecular monitoring of nematode assemblages. Wageningen University, Dissertation

Visser RGF, Jacobsen E (1993) Towards modifying plants for altered starch content and composition. Trends Biotechnol $11: 63-68$ 